\title{
Prevalence and Pattern of Refractive Errors among Primary School Children in Al Hassa, Saudi Arabia
}

\author{
Fahd Abdullah Al Wadaani ${ }^{1}$, Tarek Tawfik Amin ${ }^{2}$, Ayub Ali ${ }^{3,4}$ \& Ataur Rahman Khan ${ }^{5}$ \\ ${ }^{1}$ Department of Surgery, Ophthalmology section, College of Medicine, King Faisal University, Saudi Arabia \\ ${ }^{2}$ Community Medicine and Public Health, Faculty of Medicine, Cairo University, Cairo, Egypt \\ ${ }^{3}$ Public Health Practice \& Administration, Institute of Public Health Lahore, Pakistan \\ ${ }^{4}$ Department of Family \& Community Medicine, College of Medicine King Faisal University, Saudi Arabia \\ ${ }^{5}$ Primary Health Care, Local Health Directorate, Al Hassa, Saudi Arabia \\ Correspondence: Tarek Tawfik Amin, Associate Professor, Community Medicine and Public Health, Faculty of \\ Medicine, Cairo University, Cairo, Egypt. E-mail: amin55@myway.com
}

Received: October 29, 2012 Accepted: November 8, 2012 Online Published: November 11, 2012

doi:10.5539/gjhs.v5n1p125 URL: http://dx.doi.org/10.5539/gjhs.v5n1p125

This research project was funded by Deanship of Scientific Research, King Faisal University Al-ahsa Saudi Arabia through the Annual research Grant with Project ID \# 8029

\begin{abstract}
Some 12.8 million in the age group 5-15 years are visually impaired from uncorrected or inadequately corrected refractive errors. In Saudi Arabia, the size of this public health problem is not well defined especially among primary schoolchildren. The purpose of this cross-sectional study was to assess the prevalence and pattern of refractive errors among primary school children in Al Hassa, Saudi Arabia. A total of 2246 Saudi primary school children aged 6 to 14 years of both genders were selected using multistage sampling method form 30 primary schools located in the three different areas of Al Hassa. School children were interviewed to collect demographics and vision data using a special data collection form followed by screening for refractive errors by trained optometrists within the school premises using a standardized protocol. Assessment of visual acuity and ocular motility evaluation were carried out and cover-uncover test was performed. Children detected with defective vision were referred for further examination employing subjective refraction with auto refractometer and objective refraction using streak retinoscopy after $1 \%$ cyclopentolate. Of the screened school children $(\mathrm{N}=2002)$, the overall prevalence of refractive errors was $13.7 \%(\mathrm{n}=274)$, higher among females (Odds ratio, $\mathrm{OR}=1.39, \mathrm{P}=0.012)$ and significantly more among students of rural residence $(\mathrm{OR}=2.40, \mathrm{P}=0.001)$. The prevalence of refractive errors was disproportionately more among those aged $12-14$ years $(\mathrm{OR}=9.02, \mathrm{P}=0.001)$. Only $9.4 \%$ of students with poor vision were wore spectacles for correction. Myopia was the most commonly encountered refractive error among both genders (65.7\% of the total errors encountered). Uncorrected refractive errors affected a sizable portion of primary school children in Al Hassa, Saudi Arabia. Primary schoolchildren especially females, rural and older children represents high risk group for refractive errors for which the included children were unaware.
\end{abstract}

Keywords: refractive errors, primary schoolchildren, prevalence, Saudi Arabia

\section{Introduction}

Visual impairment due to refractive errors is one of the most common childhood problems and the second leading cause of treatable blindness (Dandona \& Dandona, 2001). It is estimated that globally 153 million people over 5 years of age are visually impaired as a result of uncorrected refractive errors, of whom 8 million are blind (WHO, 2006). Furthermore, some 12.8 million in the age group 5-15 years are visually impaired from uncorrected or inadequately corrected refractive errors, a global prevalence of $0.96 \%$, with the highest prevalence reported in urban and highly developed urban areas in south-east Asia and in China (Zhao et al., 2004). Vision disorders are the fourth most common disability of children and the leading cause of handicapping conditions in childhood (Murry \& Lopez, 1996; Ciner et al., 1998). Visual impairment from uncorrected 
refractive errors can have immediate and long-term consequences in children and adults, such as lost educational and employment opportunities, lost economic gain for individuals, families and societies, and impaired quality of life (Resnikoff et al., 2004; Larry et al., 1997). Various factors are responsible for refractive errors remaining uncorrected: lack of awareness and recognition of the problem at personal and family level, as well as at community and public health level; non-availability of and/or inability to afford refractive services for testing; insufficient provision of affordable corrective lenses; and cultural disincentives to compliance (WHO, 1993). In the age group 5-15 years, non-correction of refractive errors is due to several factors: the lack of screening, and the availability and affordability of refractive corrections are the most important. However, cultural disincentives also play a role, as shown in surveys from countries where routine screening and provision of corrections are free of charge or easily accessible, but compliance remains low (Preslan \& Novak, 1998; Khandekar et al., 2002). A remarkable finding of one study showed that even in economically advantaged societies, refractive errors can go undetected or uncorrected in children (Vitale et al., 2006). In Saudi Arabia, reliable studies that tackle the prevalence and pattern of refractive errors among primary school children are scarce, with varied results due to inconsistency in the cutoff used for errors definition form $23 \%$ in the high altitude Abha city (Abolfotouh et al., 1993) to $10.7 \%$ among pre-school children in Jeddah city at sea level (Wedad et al., 2002). Moreover, the Saudi school health services provided by ministry of education do not include adequate vision screening facilities (Wedad et al., 2002). In accordance with WHO's global initiative "Vision 2020" The right to sight (http://www.vision2020.org/main.cfm?type=WHATVISION2020), a professional based (optometry) screening program for all school-aged children is recommended to provide an early detection and initiate early treatment. The objective of the this study was determine the prevalence and pattern of refractive errors among primary school children in the age group of 6-14 years of both sexes in Al Hassa, Eastern Province, Saudi Arabia.

\section{Material and Methods}

\subsection{Setting and Design}

This is a cross-sectional study that was carried out in Al Hassa Governorate, Eastern Province of Saudi Arabia; located $50 \mathrm{~km}$ from the Arabian Gulf, $450 \mathrm{~km}$ from the capital Riyadh, and populated by about 1.5 million. Al Hassa is comprised of three regions; urban (mainly included Al Hofuf and Mubrraz cities), populated by about $60 \%$ of the total population, rural (called $\mathrm{Al}$ Omran with aggregate of several villages) consisting of 23 villages (35\% of the population) and "Hegar" Bedouin scattered communities making up the remaining $5 \%$. The Ministry of Health provides primary care through 54 PHCs, while the rest of the population are provided with primary care through other sectors e.g., National Guard, ARAMCO (oil company), military and others. School health services are provided free of charges to students in Al Hassa, through two specialized centers one each in Hofuf and in Al Omran, both providing curative/preventive primary care with referral system to the higher levels.

\subsection{Sampling and Sample Size}

Epi-Info version 2002 (CDC, Atlanta, GA, U.S.A) was used to calculate the required sample size. For this cross-sectional study design the following considerations were employed for sample size calculation: the total recorded population for the academic year 2011 was 181045 (Al Hassa Directorate of School Health records, 2011). Assuming a prevalence of refractive errors of \%11 (Wedad et al., 2002) and the worst acceptable prevalence of $9 \%$, applying a margin of error of $5 \%$ (95\% confidence), the sample size would be 936 . A design effect of 2 was considered in employing the cluster method of sampling, hence the sample size accounted to 1872. Twenty percent contingency factor was added, taking into account non responders. Thus, the final sample size was 2246 school children. A proportionate sampling method was applied with regard to the rural-urban distribution using an appropriate sampling fraction. Sampling was carried out using a multistage sampling method, first we divided Al Hassa into the three main areas for sample selection namely Al Hofuf, Mubrraz and $\mathrm{Al}$ Omran and the representation was proportional to the number of children enrolled in primary schools in each area (estimated to be 690 children from Omran, 696 from Hofuf and 860 from Mobarraz). An updated list of all public primary schools was used as the sample frame, and a total of 30 primary schools (10 from each division consisting of 5 Girls' and 5 boys' schools) were selected for this study by simple random method. Finally, the third phase was the recruitment of children aged between 6-14 years from each participating school. The class registers were used and systematic random sampling was done. Primary school children aged 6-14 years old who did not have any history of eye injuries or eye disease (e.g. corneal opacity, cataract or retinal pathology) affecting visual function were legible for inclusion.

\subsection{Methods}

\subsubsection{Demographics and Vision Data}

A special form was used to collect socio-demographic and personal including name, age, sex, history about 
present and past ocular problems and treatment and using of spectacles by students, the siblings using spectacles, results of visual acuity tests and the presence of squint.

\subsubsection{Examination for Refractive Errors}

We followed the study protocol supported by WHO named 'The Refractive Error Study in Children (RESC)' by using consistent definitions and methods (Négrel et al., 2000).

Legible school children were first screened at the school premises by the optometrists and nurses specially trained for Refractive Error Study. A standard ophthalmic examination procedure was used for each study subject. Ophthalmic examination included assessment of visual acuity for distance with Snellen's illiterate 'E' chart at room illumination and ocular motility evaluation. The distant vision of a child was tested with the chart at 6 meters Hirschberg test was performed to find out the presence of squint. A cover-uncover test was performed to confirm the diagnosis if strabismus was detected.

Children detected with defective vision were referred for further examination at three permanent ophthalmology clinics situated at the three sectors PHCs; Al Omran, Al Hofuf and Al Mubarraz. Each sector PHC has a well-established ophthalmology clinic. Referred students were further evaluated employing subjective refraction with the help of auto refractometer. In some younger children objective refraction was performed with streak retinoscopy after $1 \%$ cyclopentolate drop instilled in each eye for at least half an hour prior examination.

\subsubsection{Pilot and Filed Testing}

The study field staffs included eight nurses (4 females and 4 males) specially trained in vision screening, two optometrists, two ophthalmologists and one coordinator. Survey fieldwork was preceded by 2 weeks of staff training and all field staffs were familiarized with the standard examination procedures involved. A 5-day field exercise was performed (in a nearby two primary schools beyond those included in the final sampling) to validate the data collection and to minimize inter-observer variations. The inter-rater agreement for refractive errors (any) ranged from $93-100 \%$. For the two ophthalmologists, the inter-rater agreement for the presence of refractive errors ranged from $95-100 \%$.

\subsubsection{Definitions of Variables}

Presenting vision is the visual acuity in the better eye with the currently available refractive correction, if any.

Best corrected Vision is the visual activity in the better eye achieved either by pin hole or by refraction.

Visual impairment is the visual acuity of less than $6 / 6$ in the better eye but if it is $<6 / 18$ in the better eye it must be improved to equal to or better than $6 / 18$ by refraction or pinhole thus spanning the low vision and blindness categories as currently defined in the ICD-10.

Myopia is defined as a spherical equivalent refractive error of at least $-0.75 \mathrm{D}$ in one or both eyes.

Hypermetropia is defined as a spherical equivalent refractive error of at least $+2.00 \mathrm{D}$ or more in one or both eyes.

Astigmatism is defined (as cylinder powers $\geq 0.50$ DC or $\geq 1.00$ DC) if one or both eyes were astigmatic.

Amblyopia is defined when binocular optimal visual acuity is subnormal even after full refractive correction. Crowding phenomenon and titmus fly teat were also used to detect amblyopia.

Emmetropic eye is defined if neither eye is myopic or hypermetropia.

\section{Data Analysis}

Data analysis was done using SPSS version 17.0 (SPSS Inc. Chicago, Ill, U.S.A). Prevalence of visual impairment (visual acuity $6 / 12$ or worse) and blindness (visual acuity of $<6 / 60$ ) was calculated for uncorrected visual acuity, baseline (presenting) visual acuity, and best measured visual acuity. The latter measurement was based on subjective refraction obtained in those with reduced uncorrected visual acuity. Association of refractive error with age, sex and geographical area was explored by using Chi square test, trend analysis and Fisher Exact test.

\section{Ethical Consideration}

The study protocol was approved by the ethics committee at King Faisal University. Permissions form the Al Hassa Education Directorate and the principals of selected schools were obtained. Written consent forms from parents/legal guardians were required as a prerequisite for inclusion. Assents from selected school children were also obtained. The results of child's examination were sent to schools using a special reporting format for subsequent management by school health authorities. 


\section{Results}

Of the 2246 primary school children approached, 2002 were included with approved consent forms from thier parents/guardians with a response rate of $89.1 \%$. Those refused to participate were not significantly different in regard to their demographic characteristics.

\subsection{Demographics}

The age of the included school children ranged from 6 to 15 years with a mean of 9.4 years $(\mathrm{SD}=2.3)$ and a median of 9.5 years. Table 1 depicts the socio-demographic characteristics of the included primary school children. Urban school children represented $71.9 \%$, females constituted $51.7 \%$ and $88.3 \%$ were in the age group $<12$ years while only $11.7 \%$ were in the age range of 12 to 14 years. Grades one and six were less compared to other school grades (13.8\% for grade one and $12.7 \%$ for grade six). One percent of the included children worn spectacles, the figure were reported among their siblings.

Table 1. Demographic characteristics of the included primary school children, Al Hassa, Saudi Arabia (N=2002)

\begin{tabular}{lll}
\hline Characteristics & Number & \% \\
\hline Gender & & \\
Male & 966 & 48.3 \\
Female & 1036 & 51.7 \\
Residence & & \\
$\quad$ Rural & 561 & 28.0 \\
Urban & 1441 & 72.0 \\
Age groups (years) & & \\
$6-<9$ & 870 & 43.5 \\
$9-<12$ & 897 & 44.8 \\
$12-14$ & 235 & 11.7 \\
Mean Age & $9.48 \pm 2.31$ & \\
School grades & & \\
1 & 277 & 13.8 \\
2 & 359 & 17.9 \\
3 & 399 & 19.9 \\
4 & 353 & 17.6 \\
5 & 360 & 18.1 \\
6 & 254 & 12.7 \\
Children using spectacles & 21 & 1.0 \\
Spectacles among siblings & 20 & 1.0 \\
\hline
\end{tabular}

\subsection{Prevalence of Refractive Errors}

The overall prevalence of refractive error among the primary school children was $13.7 \%(n=274)(95 \%$ Confidence Intervals 'C.I' $=12.2 \%-15.2 \%)$, higher among females $(n=161)$ than males $(15.5 \%$ vs. $11.7 \%$, Odds ratio, $\mathrm{OR}=1.39, \mathrm{P}=0.012)$ and significantly more among students of rural residence $(123 / 561,23.71 \%)$ compared to urban $(151 / 1441,10.5 \%),(\mathrm{OR}=2.40, \mathrm{P}=0.001)$. Bilateral errors were encountered in $226(82.6 \%)$ of the children detected with refractive error, followed by right eye (10.7\%) and left eye $(6.7 \%)$.

The prevalence of refractive errors was disproportionately more among those aged $12-14$ years $(47.5 \%$, CI= $45.3-49.6 \%, \mathrm{OR}=9.02, \mathrm{P}=0.001$ ), compared to $9.8 \%$ and $8.6 \%$ in those aged $6-8$ and $9-11$ years respectively (table 2). Only $9.4 \%$ (26/274) of students with poor vision were wore spectacles for correction. About $9.0 \%$ of the siblings of the children detected with refractive errors were wearing spectacles. 
Table 2. Distribution of refractive error in relation different socio-demographic variables ( $\mathrm{N}=2002)$

\begin{tabular}{|c|c|c|c|}
\hline \multirow{2}{*}{ Variables } & \multicolumn{2}{|c|}{ Refractive errors: No. (\%) } & \multirow{2}{*}{$\begin{array}{l}\text { Odds ratio }(95 \% \text { C.I }) \text { and } \\
\text { P value }\end{array}$} \\
\hline & Present $(\mathrm{N}=274)$ & Absent $(\mathrm{N}=1728)$ & \\
\hline \multicolumn{4}{|l|}{ Gender: } \\
\hline Male & $113(11.7)$ & $853(89.1)$ & Reference \\
\hline Female & $161(15.5)$ & $875(88.5)$ & $1.39(1.06-1.81)^{*}$ \\
\hline \multicolumn{4}{|l|}{ Residence: } \\
\hline Rural & $123(21.9)$ & $438(78.1)$ & $2.40(1.83-3.14)^{* *}$ \\
\hline Urban & $151(10.5)$ & $1290(89.5)$ & Reference \\
\hline \multicolumn{4}{|l|}{ Age Groups: } \\
\hline $6-<9$ years & $85(9.8)$ & $785(90.2)$ & Reference \\
\hline $9-<12$ years & $77(8.6)$ & $820(91.8)$ & $0.43(0.32-.058)^{* *}$ \\
\hline 12-14 years & $112(47.5)$ & $123(52.3)$ & $9.02(6.59-12.35)^{* *}$ \\
\hline \multicolumn{4}{|l|}{ School grade: } \\
\hline 1 & $23(8.3)$ & $254(91.7)$ & $1.00 \dagger$ \\
\hline 2 & $37(10.3)$ & $322(89.7)$ & 1.27 \\
\hline 3 & $33(8.3)$ & $366(91.7)$ & 1.00 \\
\hline 4 & $31(8.8)$ & $322(91.2)$ & 1.06 \\
\hline 5 & $79(21.9)$ & $281(78.1)$ & 3.10 \\
\hline 6 & $71(28.0)$ & $183(72.0)$ & $4.28 * *$ \\
\hline
\end{tabular}

C.I $=$ Confidence intervals, ${ }^{*}$ P value $<0.05, * * \mathrm{P}$ value $<0.001, \uparrow$ Chi-square for trend.

\subsection{Types of Refractive Errors}

Table 3 displays the different types of refractive errors encountered among primary school children distributed in relation to gender, residence and age groups.

Table 3. Distribution of types of refractive errors by socio-demographic characteristics among the included primary school children

\begin{tabular}{|c|c|c|c|c|c|c|}
\hline \multicolumn{7}{|c|}{ Refractive errors: No. (\%) } \\
\hline Variables & $\begin{array}{l}\text { Myopia } \\
\text { (Spherical } \geq-0.75 \\
\text { D) }(\mathrm{N}=180)\end{array}$ & $\begin{array}{l}\text { Myopic } \\
\text { Astigmatism } \\
\text { (Cylindrical } \\
\geq \mathbf{0 . 7 5})(\mathrm{N}=\mathbf{3 4}) \\
\end{array}$ & $\begin{array}{l}\text { Hypermetropi } \\
\text { a (Spherical } \\
\geq 2 \text { D) }(\mathrm{N}=27)\end{array}$ & $\begin{array}{l}\text { Hypermetropic } \\
\text { astigmatism } \\
(\text { Cylindrical } \geq 0.75)(N=33)\end{array}$ & $\begin{array}{l}\text { Total } \\
(\mathrm{N}=274)\end{array}$ & $\begin{array}{l}P \\
\text { value* }\end{array}$ \\
\hline \multicolumn{7}{|l|}{ Gender: } \\
\hline Males & $70(25.5)$ & $16(5.8)$ & $14(5.1)$ & $13(4.7)$ & $113(41.2)$ & \\
\hline Females & $110(40.1)$ & $18(6.6)$ & $13(4.7)$ & $20(7.3)$ & $161(58.8)$ & 0.014 \\
\hline $\mathrm{P}$ value ** & 0.010 & 0.973 & 0.854 & 0.394 & & \\
\hline \multicolumn{7}{|l|}{$\begin{array}{l}\text { Residence } \\
\text { and Gender: }\end{array}$} \\
\hline \multicolumn{7}{|l|}{ Rural: } \\
\hline Male & $27(9.9)$ & $4(1.5)$ & $4(1.5)$ & $4(1.5)$ & $39(14.2)$ & \\
\hline Female & $69(25.2)$ & $9(3.3)$ & $3(1.1)$ & $3(1.1)$ & $84(30.7)$ & 0.001 \\
\hline \multicolumn{7}{|l|}{ Urban } \\
\hline Male & $43(15.7)$ & $12(4.4)$ & $10(3.7)$ & $9(3.3)$ & $74(27.0)$ & 0.001 \\
\hline Female & $41(15.0)$ & $9(3.3)$ & $10(3.7)$ & $17(6.2)$ & $77(28.1)$ & \\
\hline $\mathrm{P}$ value $* *$ & 0.001 & 0.252 & 0.977 & 0.494 & & \\
\hline \multicolumn{7}{|l|}{ Age groups: } \\
\hline $6-<9$ & $63(23.0)$ & $5(1.8)$ & $13(4.7)$ & $4(1.5)$ & $85(31.0)$ & \\
\hline $9-<12$ & $53(19.3)$ & $17(6.2)$ & $5(1.8)$ & $2(0.7)$ & $77(28.1)$ & 0.001 \\
\hline $12-14$ & $64(23.4)$ & $12(4.4)$ & $9(3.3)$ & $27(9.9)$ & $112(40.9)$ & \\
\hline $\mathrm{P}$ value $\dagger$ & 0.001 & 0.001 & 0.188 & -- & & \\
\hline
\end{tabular}

* Chi square for independence. ${ }^{* *} \mathrm{Z}$ test for proportions, $\dagger$ Chi square for trend. 
Myopia was the most commonly encountered refractive error among both genders $(65.7 \%)$. The prevalence of myopia accounted to $9.0 \%(\mathrm{CI}=7.7-10.2 \%)$ hypermetropia was detected in 27 students $(1.4 \%, \mathrm{CI}=0.80-1.9 \%)$, followed by myopic $34(1.7 \%, \mathrm{CI}=0.10-2.3 \%)$ and hyperopic astigmatism in $33(1.7 \%, \mathrm{CI}=1.1 \%$ to $2.2 \%)$ in the population studied.

The prevalence of myopia, myopic astigmatism, hypermetropia and hypermetropic astigmatism among those with refractive errors were accounted for $65.7 \%, 12.4 \%, 9.9 \%$ and $12.1 \%$ respectively. Simple myopia, myopic astigmatism and hypermetropic astigmatism were more prevalent among females $(31.3 \%, 6.6 \%$ and $7.3 \%$ compared to $26.8 \%, 5.8 \%$ and $4.7 \%$ in males respectively) while males had more hypermetropia ( $5.1 \%$ vs. $4.7 \%)$ than the female. Female students with rural residence were more affected compared to urban females, the prevalence of refractive errors was accounted to $30.7 \%(\mathrm{CI}=28.8-32.8 \%)$ compared to $28.1 \%$, $(\mathrm{CI}=26.6-30.6 \%)$ among urban $(\mathrm{P}=0.001)$. Also, females from rural areas were more affected with myopia as compared to urban females $(25.2 \%, \mathrm{CI}=23.3-27.1 \%$ vs. $15.0 \%, \mathrm{CI}=13.4-16.5 \%)$. Hypermetropia and hypermetropic astigmatism were more prevalent among urban than rural female $(3.7 \%, \mathrm{CI}=2.8-4.5 \%$ vs. $1.1 \%, \mathrm{CI}=0.6-1.5 \%$ for hypermetropia, and $6.2 \% \mathrm{CI}=5.2 \%-7.3 \%$ compared to $1.1 \%$, $\mathrm{CI} 0.6-1.5 \%$ for hypermetropic astigmatism).

Male students with urban residence had high frequency of myopia $(15.7 \%, \mathrm{CI}=14.1-17.3 \%$ compared to $9.9 \%$, $\mathrm{CI}=8.5-11.2 \%$ among rural males). Astigmatism was significantly more among females than males $(13.9 \%$, $\mathrm{CI}=12.4-15.4 \%$ vs. $10.6 \%$, CI $=9.2-11.9 \%)$. Urban females had high prevalence of astigmatism compared to rural females $(9.5 \%, \mathrm{CI}=8.2-10.8 \%$ compared to $4.4 \%, \mathrm{CI}=3.5-5.3 \%)$. There was an incremental relationship observed between myopia and increasing age in studies population.

Myopia was more common $(23.4 \%, \mathrm{CI}=21.5-25.2 \%)$ in the older age group (12-14 years) than in younger age groups of 6-8 years and 9-11 years where its frequency was $23.0 \%$ and $19.3 \%$ respectively. Older age group also showed increased prevalence of both myopic astigmatism (4.4\%) and hypermetropic astigmatism (9.9\%) compared to younger age group. However hypermetropia was more common $(4.7 \%)$ among the younger age group of 6-8 years as compared to the older age groups of 9-11 years (1.8\%) and $12-14$ years $(3.3 \%)$.

Amblyopia was found in $29(1.4 \%)$ of the study population. Amblyopic factors among the children with amblyopia were anisometropia $21(1.0 \%)$ and strabismus $8(0.4 \%)$.

\section{Discussion}

Visual impairment from uncorrected refractive errors can have immediate and long-term consequences in children and adults, such as lost educational and employment opportunities, lost economic gain for individuals, families and societies, and impaired quality of life (Resnikoff et al., 2004). Various factors are responsible for refractive errors remaining uncorrected: lack of awareness and recognition of the problem at personal and family level, as well as at community and public health level; non-availability of and/or inability to afford refractive services for testing; insufficient provision of affordable corrective lenses; and cultural disincentives to compliance (WHO, 2003).

The estimate of visual impairment caused by uncorrected refractive errors is of public health concern (Resikoff et al., 2004; Thylefors, 1998; Dandona \& Dandona., 2001) despite that refractive errors could be easily diagnosed and that spectacle correction is among the most cost-effective interventions in eye care. According to Baltussen et al. (2008), screening of 5-15 years old yields the most health effects and more absolute terms, both screening of 10-15 years and 5-15 years old are very cost-effective strategies. Therefore screening of the school children is an important measure to know the magnitude of refractive error and their correction at the appropriate time.

In this study $13.7 \%$ of the screened primary school children were positive for uncorrected refractive errors. The prevalence of refractive errors among our sample of primary school children which was higher than that reported form similar study conducted in Saudi Arabia (AI Rowaily \& Alanizi, 2010) of 9.8\% among intermediate school students, Malaysia, 7.7\% (Hashim et al., 2008), Nepal 8.6\% (Pokharel et al., 2010), Iran 3.5\% (Fotouhi et al., 2007), Uganda 11.6\% (Kawuma \& Mayeku, 2002) and Bangkok 12.7\% (Yingyong, 2010) and lower than those reported from Qatar of 19.7\% (AL-Nuaimi et al., 2008), and India (Padhye et al., 2009) of 25.1\% [Table 4]. 
Table 4. Prevalence of refractive errors among school children in different parts of the world

\begin{tabular}{lllll}
\hline Country & Year & Age group & Sample size & Prevalence of refractive errors \\
\hline Iran & 2007 & $6-17$ & 5544 & $3.8 \%$ \\
Malaysia & 2008 & $6-12$ & 840 & $7.7 \%$ \\
Nepal & 2011 & $5-16$ & 2236 & $8.6 \%$ \\
Uganda & 2002 & $6-9$ & 623 & $11.6 \%$ \\
Bangkok & 2010 & $6-12$ & 1100 & $12.7 \%$ \\
India & 2007 & $6-12$ & 2317 & $25.1 \%$ \\
Qatar & 2010 & $6-13$ & 670 & $19.7 \%$ \\
Saudi Arabia & 2010 & $12-13$ & 1536 & $9.8 \%$ \\
Saudi Arabia Current & 2011 & $6-14$ & 2002 & $13.7 \%$ \\
\hline
\end{tabular}

This variation may be related to the type of sampling method used, size of population screened and the variation of geographical location in these studies. Unlike other studies where higher prevalence of refractive error has been documented in urban population (Pokharel et al., 2010; Fotouhi et al., 2007; Kawuma \& Mayeku, 2002; AL-Nuaimi et al., 2010; Padhye et al., 2009), our study has found higher prevalence of refractive among rural schoolchildren. However Ahuama and Atowa (1987) in their population based study in Uganda had found a higher prevalence of refractive error in rural area than urban (29.0\% compared to $21.6 \%$ among urban students).

Higher prevalence of refractive errors in rural area may be attributed to the rapid urbanization in Saudi Arabia (Basha, 1992) with greater access to and abundance of computers and electronic gadgets as a result of advanced socio-economic transition coupled with the availability and regularity of electricity which have motivated children to remain indoors and involved in activities which cause more eye strain.

We have found a higher prevalence of refractive error among female students than males. This is consistent with similar studies carried out in Riyadh, Saudi Arabia among intermediate school students where it was reported a prevalence of $11.7 \%$ among females compared to $8.3 \%$ among males (AI Rowaily \& Alanizi, 2010), similar findings were reported form Qatar (AL-Nuaimi et al., 2008) with 23.7\% prevalence of refractive errors among females compared to $15.5 \%$ among males), India (Prema, 2011) with $17.2 \%$ vs. $13.4 \%$ among males, Ghana (Ovenseri-Ogbomo \& Assien, 2010) and Germany (Jobke et al., 2008).

Of the encountered refractive errors in this study, myopia was the leading type found representing $65.7 \%$ which is consistent with other studies done in various parts of the world. The research conducted in Malaysia (Hashim et al., 2008), Nepal (Pokharel et al., 2010), India (Padhye et al., 2009), Jordan (Bataineh \& Khatatbeh, 2009) and Qatar (Al-Naimi et al., 2010) have found that myopia represented 77.5\%, 59.8\%, 20.65\%, 31.05\%, 63.5\% and $25.54 \%$ of screened errors respectively among 6-14 years schoolchildren.

In our study the rate of myopia was significantly higher in rural children. This is in contrast to other studies where the prevalence of myopia has been found to be higher in urban area than rural (Hashim et al., 2008; Pokharel et al., 2010; Padhye et al., 2009). This may be due to different definitions of myopia used in these studies $(<-.50 \mathrm{D})$. We used $->0.75 \mathrm{D}$ as the myopic definition. Other reason for this increased myopia in rural area may be due to decreased outdoor activities in rural children than the urban. Nevertheless, for the age group 5-15 years, the prevalence of visual impairment from uncorrected refractive errors in some regions appears to be higher in urban areas than in rural areas, despite the reported better access to services. This may be due to a high incidence of myopia in these populations: it is suggested that there may be a direct cause-effect relation between increased access to education and myopia, but other secular changes could be contributing factors (Resnikoff et al., 2004).

During the last three decades Saudi Arabia has witnessed an increasing mushroom growth of parks, super malls and gyms in all urban areas including $\mathrm{Al}$ Hassa, thereby increasing the outdoor recreational activities for urban children. Studies form Australia, Singapore, United States and Turkey has shown that outdoor activities act as a protective factor for myopia (Rose et al., 2008; Ip et al., 2008; Onal et al., 2007; Mutti et al., 2002; Jones et al., 2007). It must be mentioned that the students were screened for distant vision only hence, number of hypermetropia is far less than myopic ones.

In the current study we have found a high prevalence of astigmatism (24.5\%), similar results have been reported form Qatar (70\%) (Al-Naimi et al., 2010), Ghana (49.3\%) (Ovenseri-Ogbomo \& Assien, 2010), Pakistan (35.5\%) (Ali et al., 2007) and Jordan (20.4\%) (Bataineh \& Khatatbeh 2008) and contrary to those found in Nepal (9.2\%) 
(Pokharel, 2010) and China (8.3\%) (Rose et al., 2010).

These findings warrant the urgent implementation of fundamental policies including screening of children for refractive errors that should be conducted at community level and integrated into school health programs, accompanied by education and awareness campaigns to ensure that the corrections are used and cultural barriers to compliance are addressed and removed. Corrections must be accessible and affordable for people of all age especially those at school age. Training and information program should also be tailored for teachers and school health-care workers. There is a need to conduct this type of study in different parts of Saudi Arabia to know national magnitude of the refractive error which will help the health authority to formulate appropriate strategy for effective screening program throughout the country.

\section{Study Limitations}

The potential effects of the encountered errors in the form of scholastic achievements were not studied; also the possible risk factors responsible for the development of the different types of errors were not possible due to difficulties inherent with the used research design.

\section{Conclusion}

Uncorrected refractive errors affected a sizable portion of primary school children in Al Hassa, Saudi Arabia. Primary schoolchildren especially females and rural children represents high risk group for refractive errors for which the included children were unaware. Periodic screening in schools should be carried out; school teachers, children and their parents should be educated about signs and symptoms of refractive errors and for the risk factors involved in their development.

\section{References}

Ali, A., Imran, A., \& Ayub, S. (2007). Prevalence of uncorrected refractive errors among school children, E:/Biomedica, 23. Retrieved from http://thebiomedicapk.com/articles/118.pdf

Ahuama, O. C., \& Atowa, U. C. (1987). Distribution of refractive errors among school children in Abia state of Nigeria. Journal Ophthalmic Physiological Optics, 7(3), 241-244.

AL-Nuaimi, A. A., Salama, R. E., \& Eljack, I. E. (2010). Study of refractive errors among school children Doha. World Family Medicine Journal, 8(7), 41-48.

AI Rowaily, M. A., \& Alanizi, B. M. (2010). Prevalence of Uncorrected Refractive Errors among Adolescents at King Abdul-Aziz Medical City, Riyadh, Saudi Arabia. Journal Clinical Experimental Ophthalmology, 1, 114. http://dx.doi.org/10.4172/2155-9570.1000114

Baltussen, R., Naus, J., \& Limburg, H. (2009). Cost-effectiveness of screening and correcting refractive errors in school children in Africa, Asia, America and Europe. Health Policy, 89(2), 201-1. http://dx.doi.org/10.1016/j.healthpol.2008.06.003

Basha, A. A. (1992). University of Pennsylvania: Migration and urbanization in Saudi Arabia: The case of Jeddah and Riyadh. Retrieved October 15, 2012, from http://repository.upenn.edu/dissertations/AAI8824713/

Bataineh, H. A., \& Khatatbeh, A. E. (2008). Prevalence of Refractive Errors in School Children. Sudanese Journal of Public Health, 3(4), 23-29.

Ciner, E. B., Schmidt, P. P., Orel-Bixer, D., Velma, D., Maureen, M., Lynn, C., ... Janet, S. (1998). Vision screening of preschool children: Evaluating the past, looking forward the future. Optometry and Vision Science, 75(5), 571-584. http://dx.doi.org/10.1097/00006324-199808000-00022

Dandona, R., \& Dandona, L. (2001). Refractive error blindness. Bulletin World Health Organization 79: 237-43.

Fotouhi, A., Hashemi, H., Khabazkhoob, M., \& Mohammad, K. (2007). The prevalence of refractive errors among schoolchildren in Dezful, Iran. British Journal of Ophthalmology, 91, 287-29. http://dx.doi.org/10.1136/bjo.2006.099937

Hashim, S. E., Tan, H. K., Wan-Hazabbah, W. H., \& Ibrahim, M. (2008). Prevalence of Refractive Error in Malay Primary School Children in Suburban Area of Kota Bharu, Kelantan, Malaysia. Annals Academic Medicine Singapore, 37, 940-6.

Ip, J. M., Saw, S. M., Rose, K. A., Morgan, I. G., Kifley, A., Wang, J. J., \& Mitchell, P. (2008). Role of near work in myopia: findings in a sample of Australian school children. Investigative Ophthalmology and Vision Science, 49, 2903-10. http://dx.doi.org/10.1167/iovs.07-0804

Jones, L. A., Sinnott, L. T., Mutti, D. O., Mitchell, G. L., Moeschberger, M. L., \& Zadnik, K. (2007). Parental 
history of myopia, sports and outdoor activities, and future myopia. Investigative Ophthalmology and Vision Science, 48, 3524-32. http://dx.doi.org/10.1167/iovs.06-1118

Jobke, S., Kasten, E., \& Vorwerk, C. (2008). The prevalence rates of refractive errors among children, adolescents, and adults in Germany. Clinical Ophthalmology, 2(3), 601. http://dx.doi.org/10.2147/OPTH.S2836

Kawuma, M., \& Mayeku, R. (2002). A survey of the prevalence of refractive errors among children in lower primary schools in Kampala district. African Health Science, 2(2), 69-72.

Khandekar, R., Mohammed, A. J., \& Al Raisi, A. (2002). The compliance of spectacle wear and its determinants among school children of Dhakhiliya region of the Sultanate of Oman. A descriptive study. Sultan Qaboos University Journal for Scientific Research \& Medical Sciences, 4, 39-42.

Larry, N. T., Wheeler, W., \& Douglas, H. (1997). Power vectors: an application of Fourier analysis to the description and statistical analysis of refractive error. Optometry and Vision Science, 74(6), 367-375. http://dx.doi.org/10.1097/00006324-199706000-00019

Murray, C. J. L., \& Lopez, A. D. (1996). Editors. The global burden of disease: a comprehensive assessment of mortality and disability from diseases, injuries and risk factors in 1990 and projected to 2020 [Global Burden of Disease and Injury Series, Vol. 1]. Cambridge: Harvard School of Public Health on behalf of the World Health Organization and the World Bank; 1996.

Mutti, D. O., Mitchell, G. L., Moeschberger, M. L., Jones, L. A., \& Zadnik, K. (2002). Parental myopia, near work, school achievement, and children's refractive error. Investigative Ophthalmology and Vision Science, 43, 3633-40.

Négrel, A. D., Maul, E., Pokharel, G. P., Zhao, J., \& Ellwein, L. B. (2000). Refractive error study in children: sampling and measurement methods for a multi-country survey. American Journal of Ophthalmology, 129, 421-6. http://dx.doi.org/10.1016/S0002-9394(99)00455-9

Onal, S., Toker, E., Akingol, Z., Arslan, G., Ertan, S., Turan, C., \& Kaplan, O. (2007). Refractive errors of medical students in Turkey: one year follow-up of refraction and biometry. Optometry and Vision Science, 84, 175-80. http://dx.doi.org/10.1097/OPX.0b013e3180335c52

Ovenseri-Ogbomo, G. O., \& Assien, R. (2010). Refractive error in school children in Agona Swedru, Ghana. South African Journal of Optometry, 69(2), 86-92.

Padhye, A. S., Khandekar, R., Dharmadhikari, S., Dole, K., Gogate, P., \& Deshpande, M. (2009). Prevalence of uncorrected refractive error and other eye problems among urban and rural school children. East African Journal of Ophthalmology, 16, 69-74. http://dx.doi.org/10.4103/0974-9233.53864

Pi, L. H., Chen, L., Liu, Q., Ke, N., Fang, J., Zhang, S., ... Yin, Z. Q. (2010). Refractive Status and Prevalence of Refractive Errors in Suburban School-age Children. International Journal of Medical Science, 7(6), 342-353. http://dx.doi.org/10.7150/ijms.7.342

Pokharel, A., Pokharel, P. K., Das, H., \& Adhikari, S. (2010). The patterns of refractive errors among the school children of rural and urban settings in Nepal, Nepalese Journal of Ophthalmology, 2(2), 15-27. http://dx.doi.org/10.3126/nepjoph.v2i2.3717

Powell, C., Wedner, S., \& Hatt, S. R. (2006). Vision screening for correctable visual acuity deficits in school-age children and adolescents. Cochrane Database of Systematic Reviews (2). Art. No.: CD005023.

Prema, N. (2011). Prevalence of refractive errors in school children. Indian Journal Science Technology, 4, 9.

Preslan, M. W., \& Novak, A. (1998). Baltimore vision screening project. Phase 2 Ophthalmology, 105, 150-3.

Resnikoff, S., Pascolini, D., Mariotti, S. P., \& Pokharel, G. P. (2004). Global magnitude of visual impairment caused by uncorrected refractive errors in 2004. WHO bulletin, Geneva. http://www.who.int/bulletin/volumes/86/1/07-041210/en/index.html

Rose, K. A., Morgan, I. G., Smith, W., Burlutsky, G., Mitchell, P., \& Saw, S. M. (2008). Myopia, lifestyle, and schooling in students of Chinese ethnicity in Singapore and Sydney. Achieve of Ophthalmology, 126, 527-30. http://dx.doi.org/10.1001/archopht.126.4.527

Thylefors, B. (1998). A global initiative for the elimination of avoidable blindness. American Journal of Ophthalmology, 125, 90-3. http://dx.doi.org/10.1016/S0002-9394(99)80239-6

Vitale, S., Cotch, M. F., \& Sperduto, R. D. (2006). Prevalence of visual impairment in the United States. JAMA, 
295, 2158-63. http://dx.doi.org/10.1001/jama.295.18.2158

Wedad, M., Bardisi Bakr, M., \& bin Sadiq (2002). Vision screening of preschool children in Jeddah, Saudi Arabia. Saudi Medical Journal, 23(4), 44-449.

WHO. (1993). International statistical classification of diseases, injuries and causes of death, tenth revision. Geneva: WHO; 1993.

WHO's global initiative. (Vision 2020). http://www.vision2020.org/main.cfm?type=WHATVISION2020

WHO. (2001). Prevention of Blindness and Deafness. Elimination of avoidable visual disability due to refractive errors. Report of an informal planning meeting. Geneva, 3-5 July 2000. Geneva: WHO; 2001 (WHO/PBL/00.79).

WHO. (2006). Prevention of Blindness and Deafness. Available data on blindness, update 2006. Geneva: WHO; 2006. Retrieved from http://www.who.int/blindness/publications/global_data.pdf

Zhao, J., Mao, J., Luo, R., Li, F., Pokharel, G. P., \& Ellwein, L. B. (2004). Accuracy of noncycloplegic autorefraction in school-age children in China. Optometry and Vision Science, 81, 49-55. http://dx.doi.org/10.1097/00006324-200401000-00010

Yingyong, P. (2010). Refractive errors survey in primary school children (6-12 year old) in 2 provinces: Bangkok and Nakhonpathom (one year result). Journal Medical Association of Thailand Chotmaihet Thangphaet, 93(10), 1205-1210. 